\title{
Improvement of an automated CAN packaging system based on modeling and analysis approach through robot simulation tools
}

\author{
Khongsak Srasrisom ${ }^{1}$, Pramot Srinoi $^{2}$, Seksan Chaijit ${ }^{3}$, Fasai Wiwatwongwana ${ }^{4}$ \\ ${ }^{1,3,4}$ Department of Advanced Manufacturing Technology, Pathumwan Institute of Technology, Thailand \\ ${ }^{2}$ Department of Industrial Engineering, Kasem Bundit University, Thailand
}

\section{Article Info \\ Article history: \\ Received Jan 7, 2020 \\ Revised Feb 18, 2020 \\ Accepted Mar 4, 2020 \\ Keywords: \\ DELMIA V6 \\ Modelling \\ Palletizing \\ Robot simulation tools \\ Robotic manipulator}

\begin{abstract}
The application of robot simulation tools for modelling, analysis and improvement of existing industrial manufacturing cells is presented with reference to the development and implementation of the digital factory concept. A real case study of aerosol can packaging and palletizing cell scenario in the metal can manufacturing industry for containing food and products is used as a reference in this paper. For studying manual aerosol can packaging and palletizing conditions of the worker, a detailed Time and Motion analysis of workers is carried out. On the basis of cycle time analysis results, an alternative to the manual operation, a more sophisticated automated packaging and palletizing system is suggested. A proposed system which uses a robotic manipulator including automated production machine and devices are also developed and tested. The viability of the suggested system is checked through simulation and cycle time analysis. A fuzzy logic software, MATLAB is employed in order to analyse the actual system's behaviour in terms of productivity, and utilization of the available facilities. The 3D simulation software, DELMIA V6 is additionally employed to perform a detailed design phase of the manufacturing cell. From the simulation results, this gives a rough approximation that the production of one robotized manipulator, and automated packaging and palletizing cell is equal to the production of about 4.3 manual packaging and palletizing cells. These results have shown the need for change to automation in the aerosol can packaging and palletizing system.
\end{abstract}

This is an open access article under the CC BY-SA license.

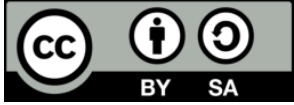

\section{Corresponding Author:}

Khongsak Srasrisom,

Department of Advanced Manufacturing Technology,

Pathumwan Institute of Technology,

833 Rama1 Road, Pathumwan, Bangkok 10330, Thailand.

Email: khongsaksss67@gmail.com

\section{INTRODUCTION}

Contemporary manufacturing systems should be subject to continuous upgrading consistent with the very fast transformation of market requirements and the frequent launch of technology innovations [1, 2]. Methods based on mathematical analysis and physical experimentation are often employed for the design and improvement of manufacturing systems: however, digital modelling and simulation tools can reduce design time and cost in case of complex systems $[3,4]$.

In recent years, a new approach based on digital methodologies and tools has been developed to optimize manufacturing systems design and reconfiguration: the Digital Factory [5, 6]. The latter represents a very effective instrument for enhancing legacy manufacturing systems as well as for conceiving entirely new systems. In the Digital Factory approach, simulation has a central function; it can be applied to support decision making on the appropriate strategy to adopt as it allows a set of decision variables to be mapped to 
a proper set of performance measures which are essential to appreciate the behavior of a manufacturing system [7-9]. Manufacturing performance measures offer the capability to reproduce the actual state of a manufacturing system, monitor and control the operational efficiency, drive improvement strategies, and verify manufacturing decisions effectiveness $[10,11]$.

Currently, increasing use of automation and robotization can be seen, which replaces human labor. Industrial robots have mobility similar to that of the human arm, and can perform various complex actions similarly to a human. It is estimated that, thanks to robotization, many companies have obtained a reduction in production costs of $50 \%$, an increase in productivity of $30 \%$, and an increase in utilization of more than $85 \%$ [12].

There are several digital simulation tools to choose from, both during the design and the operation of a manufacturing system. Facility layout as well as material handling system selection and configuration can be supported by tools such as 3D Motion Simulation [13]. In order to perform a comprehensive analysis taking into account aspects related to robot motion, as the possibility to reach all the objectives, safety of movements throughout the manufacturing cell and the configuration of a suitable layout, the 3D simulation software DELMIA V5 was additionally employed to perform a detailed design phase of the manufacturing cell. The results of this 3D simulation concerned layout modifications and the estimated robot loading/unloading and travel times.

Robotic simulation is a powerful tool which is extensively useful in industry in order to save money and end users' time while designing a robotic workcell. Users can predict the behavior of workcell prior setting up actual process and thus can save both time and money. Robotic simulation allows smoother transition from concept to reality giving users freedom to make mistakes, study and analyze them while designing the workcell. Many industries are now recognizing simulation as a viable tool as it provides better manufacturing designs and also offers cost benefits in engineering and installation benefits [14]. Robotic simulation is a kinematics simulation tool which primary uses are as a highly detail, cell-level validation tool [15] and for simulating a system whose state changes continuously based on the motion(s) of one or more kinematic devices [16].

The research work illustrated in this paper is carried out in the metal can manufacturing industry for containing food and products. Currently, the process of aerosol can packaging and palletizing in this manufacturing cell is operated manually by the worker. The operation to automate in the metal can manufacturing industry is related to the development and implementation of the Digital Factory concept through the application of robot simulation tools for modelling, analysis and improvement of real manufacturing cells.

The analysis and improvement of a manufacturing cell are typically carried out through a decision making process involving several issues to be taken into consideration. Robot simulation tools are very effective to support this process, as they enable dealing with a number of aspects as diverse as facility layout, material handling system design, manufacturing system capacity and throughput analysis.

In this research work, the fuzzy logic approach is employed to analyse the automated CANs packaging cell in terms of productivity and utilization of available resources. The numerical analysis results are performed to suggest possible improvement actions that could increase efficiency and productivity of the automated CANs packaging cell. In addition, the process of an aerosol can packaging and palletizing system, composed of a robot manipulator and automated production machine and devices is modelled and simulated via Delmia V6 software with the aim to examine and improve performance. The simulation will focus on activities of robot manipulator in de-palletizing, material handling, packaging, unloading, and palletizing throughout the workcell. The analysis and procurement of that automation will greatly improve the productivity and cost effectiveness of this manufacturing industry.

\section{CURRENT MANUFACTURING WORKCELL}

\subsection{Aerosol can packaging and palletizing process}

In our case study, the production industry of aerosol cans used to contain chemicals, in which the process of packaging 12 aerosol cans into a cardboard carton and palletizing is a manufacturing scenario. However, as mentioned in Section 1, the current workcell still employs workers for aerosol can packaging and palletizing as shown in Figure 1.

The procedure of aerosol can packaging and palletizing, by a total of six workers is as follows:

Forming a cardboard carton and assembling a 12 compartments partition, and then putting an assembled partition into the cardboard carton, with three workers as shown in Figure 1(a).

- Moving the assembled cardboard carton to the assembly station, with one worker, and the another one worker packaging the aerosol cans in a cardboard carton, and sealing it, as shown in Figure 1(b).

Moving the sealed aerosol cans carton, and palletizing, with one worker as shown in Figure 1(c). 


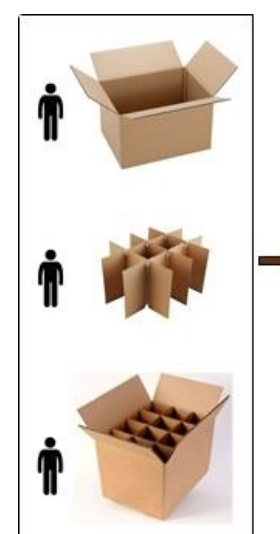

(a)

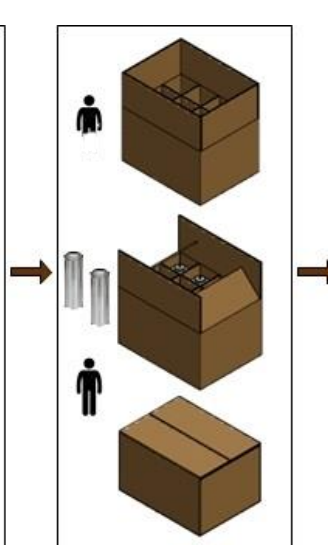

(b)

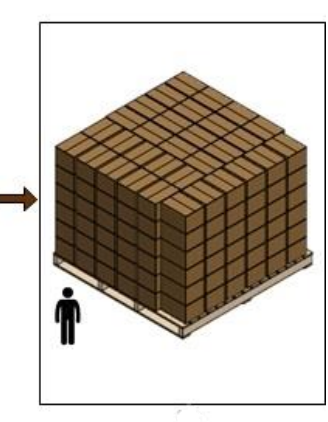

(c)

Figure 1. Manual aerosol cans packaging and palletizing: (a) carton board with 3 workers, (b) assembly station with one worker, and (c) palletizing with one worker

\subsection{Current workcell analysis}

The cycle time analysis, work with people, is referred to as human cycle time $(C T)$ using one of the work measurement technics called Method Time Measurement (MTM) of a person who has been given a real-time workout. The human cycle time of aerosol cans packaging and palletizing as mentioned in Section 2.1 can be expressed as in (1):

$$
C T=\sum_{i=1}^{n} t_{i}
$$

where $C T=$ cycle time, $\sec / \mathrm{pa} ; t_{i}=$ material handling/assembly operation time at workstation $i$, sec; $i=$ workstation.

The production rate $\left(R_{p}\right)$ of a human workcell can be illustrated as in (2):

$$
R_{p}=\frac{60}{T_{p}}
$$

where $R_{p}$ is expressed in work units per hour, $\mathrm{pa} / \mathrm{hr} ; T_{p}=$ production time per work unit on the workstation that takes the longest, min.

Here, the production time measurement of one pack on each workstation, respectively, is shown in Table 1. It is seen that the cycle time of a human workcell for packaging aerosol cans in one pack, and then palletizing, can be obtained from (1), therefore,

$$
C T=15+20+10+10+30+15=100 \mathrm{sec}
$$

It is also seen that, aerosol cans packaging at workstation 5, takes the longest, that is,

$$
T_{p}=30 \mathrm{sec}=30 / 60=0.5 \mathrm{~min}
$$

Calculate the production rate from (2) will be:

$$
R_{p}=\frac{60}{0.5}=120 \mathrm{pas} / \mathrm{hr}
$$

If speeding up the demands of the job is needed, it is only possible to reduce the $C T$. However, there are certain effects and physical demands of speeding up the demands of the job by reducing the $C T$ [17]. It results in muscle pain and tenderness of the neck and shoulder areas, are also common in repetitive tasks, if the $C T$ is reduced. Therefore, in order to increase production rate to meet demand, it is possible is to add workcells or work shifts. However, operating cost will be increased as well. For that reason, automating in packaging and palletizing systems is suggested. 
Table 1. The production time per 1 pack in each work station.

\begin{tabular}{cccc}
\hline Workstation & No. of worker (person) & Work procedures & Production time (sec) \\
\hline 1 & 1 & Cardboard carton forming & 15 \\
2 & 1 & Partition assembling & 20 \\
3 & 1 & Putting an assembled partition & 10 \\
4 & 1 & Carton preparing & 10 \\
5 & 1 & Aerosol cans packaging & 30 \\
6 & 1 & Palletizing & 15 \\
\hline
\end{tabular}

\section{DEVELOPMENT OF AUTOMATED CAN PACKAGING CELL}

\subsection{Conceptual design}

From the study and analysis of the workcell of the current system, there is a concept to design a system with a working process are: 1) arranging the aerosol cans in the form of 12 cans, 2) placing a group of aerosol cans into an assembled carton, 3) sealing the canned carton, and 4) palletizing the sealed can as shown in Figure 2. It is seen that, the speeding up the demands of the job can be done with automated production machines and devices instead of human workers.

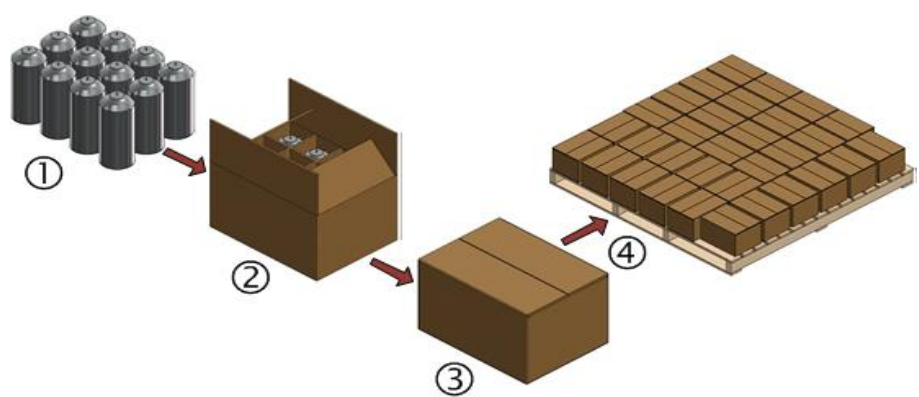

Figure 2. Conceptual design

\subsection{Analysis of CAN packaging cell}

Fuzzy Logic approach is employed to analyse the automated CANs packaging cell in terms of productivity and utilization of available resources. The fuzzy model for production rate is shown in Figure 3. In this research, three inputs, transferring rate $(T r)$, packaging rate $(P k)$ and palletizing rate $(P l)$, and one output fuzzy variable, production rate $(R p)$ are considered. The membership functions for each fuzzy set are triangular except at the extreme left are assumed. Universe of discourse of the variables is defined as:

$$
\begin{aligned}
& T r=[0.8,16] \\
& P k=[0.0,15] \\
& P l=[0.0,16] \\
& R p=[0.0,20]
\end{aligned}
$$

When three inputs are entered into the system, a crisp output will be obtained for production rate as shown in Figure 4.

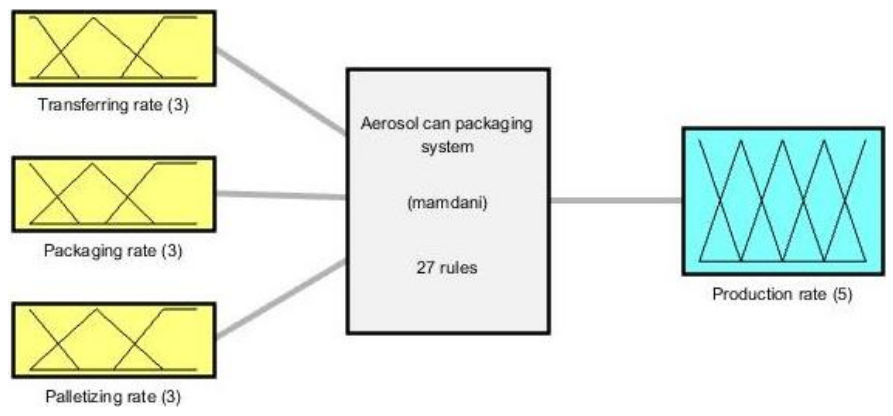

Figure 3. Fuzzy model for production rate 


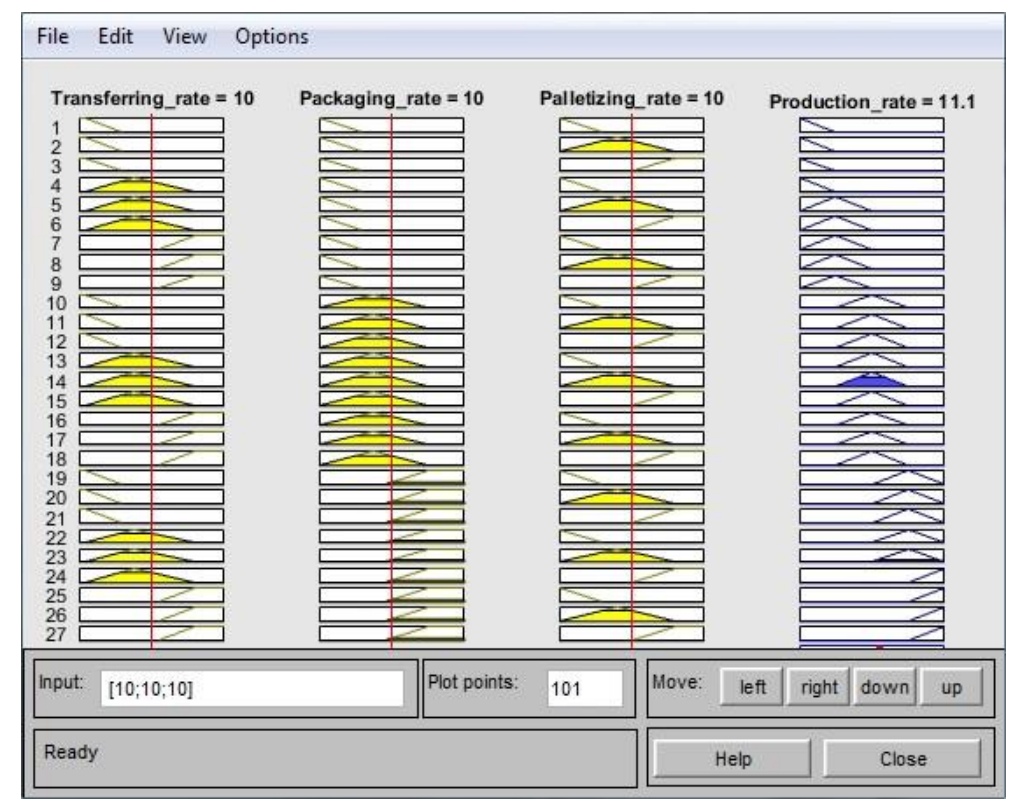

Figure 4. Crisp output for production rate

\subsection{Robotic workcell modeling}

The methodology for developing the automated CANs packaging cell is based on the conceptual design in Section 3.1. Using Delmia V6 software, the following steps are:

a. Modeling of 3D geometry:

Automated CANs packaging cell here consists of robot manipulator, and automated production machine and devices are modeled as the robotic workcell is shown in Figure 5. The sequence of robotic workcell working is determined as follows.

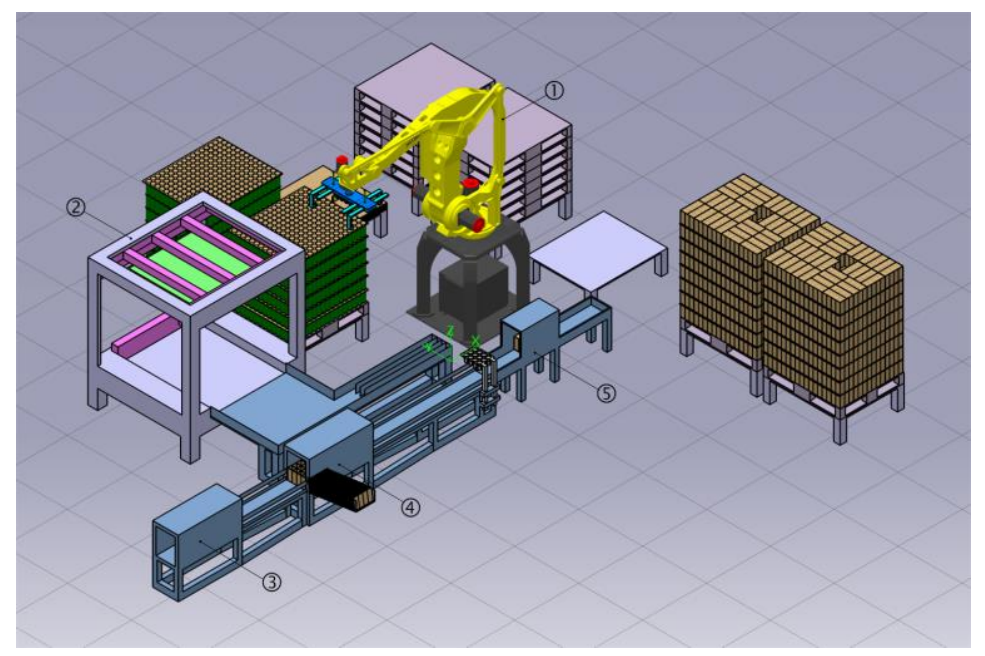

Figure 5. Robotic workcell

- A joint arm robot (1) picks cardboard covering the top of the incoming aerosol can pallet, and places it on the cardboard stack. The joint arm robot then moves back to pick an empty pallet and place it on the support base.

- An automatic can transferring machine (2) loads 228 aerosol cans at a time, then transfers them to the end of the feed track divided into four channels. 
- At the same time, the cardboard will be folded in this automatic case erector (3), then the cardboard carton is forwarded to the automatic partition assembler (4) in order to assembly a 12 compartments partition, and then the assembled cardboard carton is transported to the end of conveyor, wait for packaging.

- The joint arm robot picks 12 aerosol cans at a time from the end of the feed track, then moving to the conveyor, places all the cans in the carton. The aerosol canned carton is then conveyed to an automatic carton sealer (5) to seal this carton using tape.

- The joint arm robot moves to pick the sealed carton one by one, then do the palletizing. The joint arm robot then goes back and repeats in step 4 for a total of 19 times, considered as 1 cycle time.

b. Defining of work cell component parameters:

Analysis of the results in Section 3.2 is carried out to suggest possible areas of improvement that could increase efficiency and productivity, and a reconfiguration of automated CAN packaging cell through integration of a robotic material handling system is proposed. It provides the ability to select and position the various components of the active devices and tools including joint arm robot and sensors. The workcell components having following specifications: 1) 6 axes joint arm robot; robot motion speed, $\mathrm{J} 1=210^{\circ} / \mathrm{s}$, $\mathrm{J} 2=190 \% \mathrm{~s}, \mathrm{~J} 3=210 \% \mathrm{~s}, \mathrm{~J} 4=400 \% \mathrm{~s}, \mathrm{~J} 5=400 \%$, and $\mathrm{J} 6=600 \% \mathrm{~s}, 2)$ automatic can transferring machine; $240 \mathrm{cans} / \mathrm{min}, 3)$ automatic case erector; $20 \mathrm{pas} / \mathrm{min}, 4)$ automatic partition assembler; $20 \mathrm{pas} / \mathrm{min}$, and 5) automatic carton sealer; 20 pas/min.

The automated CANs packaging cell process is shown as a Pert process chart in Figure 6, which consists of 3 workstations: 1) ST1-Robotic_Act_01 represents the joint arm robot, 2) ST2-Gantry_Act_01 represents the automatic cans transferring machine, and 3) ST3-Modular_Act_01 represents the automatic case erector, partition assembler, and carton sealer as shown in Figure 7, 8, and 9 respectively.

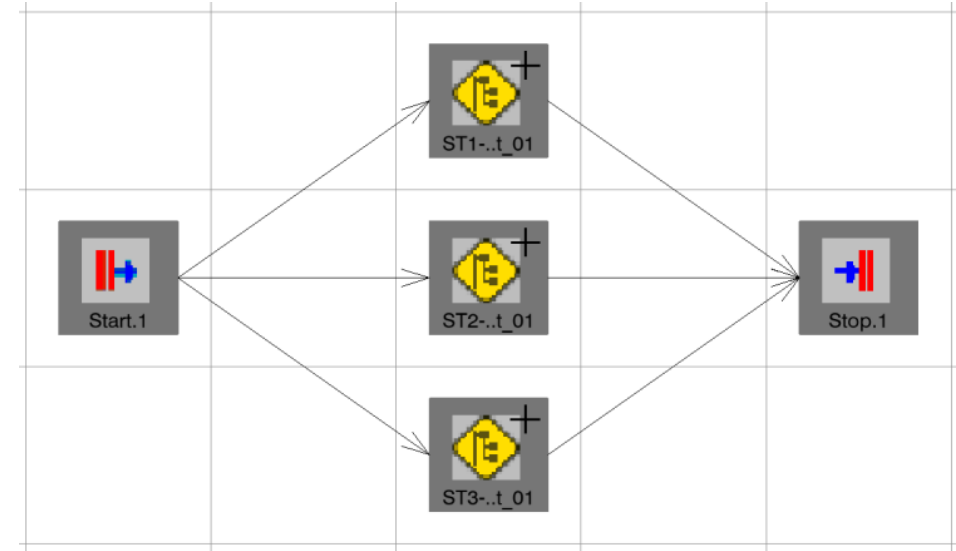

Figure 6. System PERT process chart

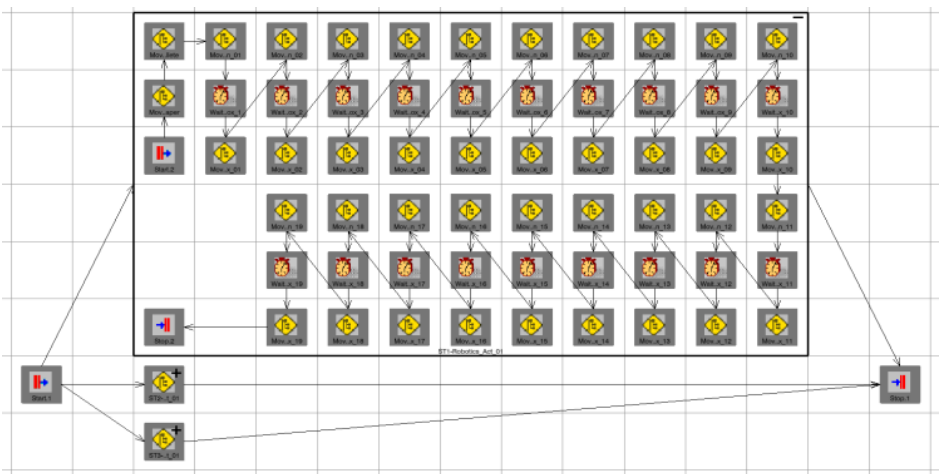

Figure 7. Workstation ST1-Robotic_Act_01 


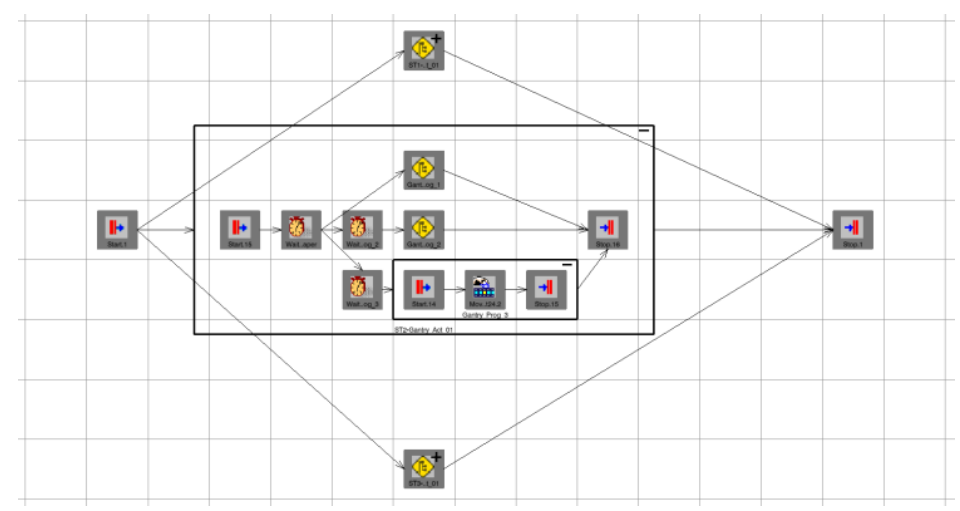

Figure 8. Workstation ST2-Gantry_Act_01

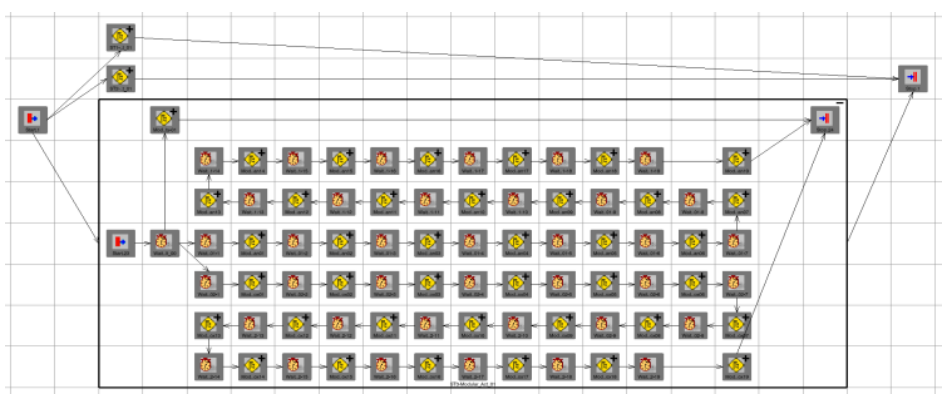

Figure 9. Workstation ST3-Modular_Act_01

\subsection{Simulation}

This uses geometric modeling and kinematic analysis to simulate the movement of a robotic manipulator and production machine and devices. The best performance of simulation of the robotic workcell can be demonstrated by the process Gantt chart in Figure 10 (a), (b), and (c). In this paper, it shows the Gantt chart of the joint arm robot in each activity only throughout the cycle time, which is $554.97 \mathrm{sec}$, as shown in Figure 11 (a), (b), and (c).

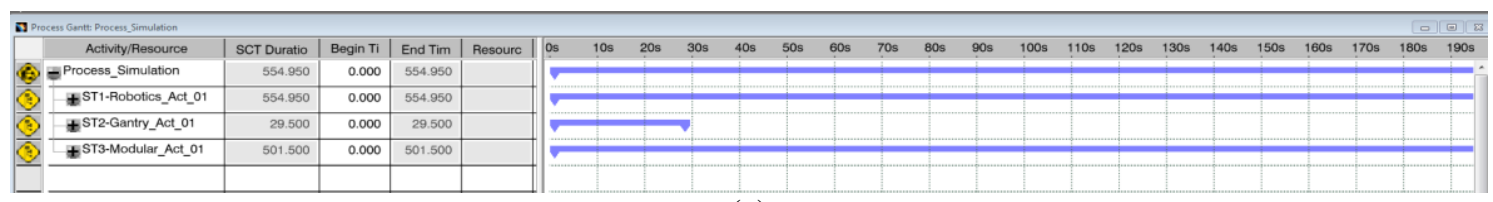

(a)

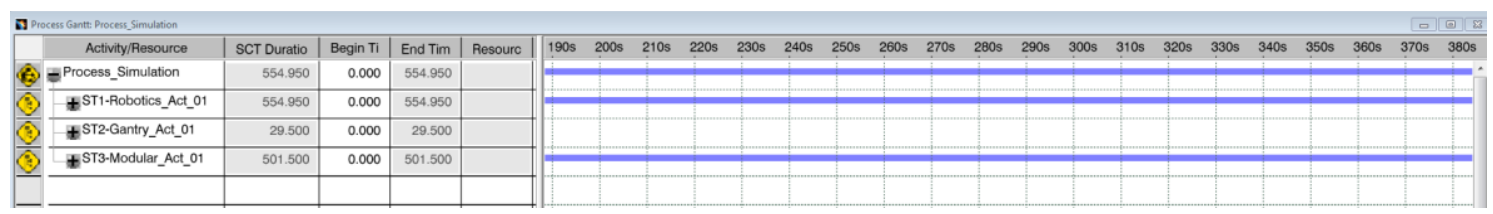

(b)

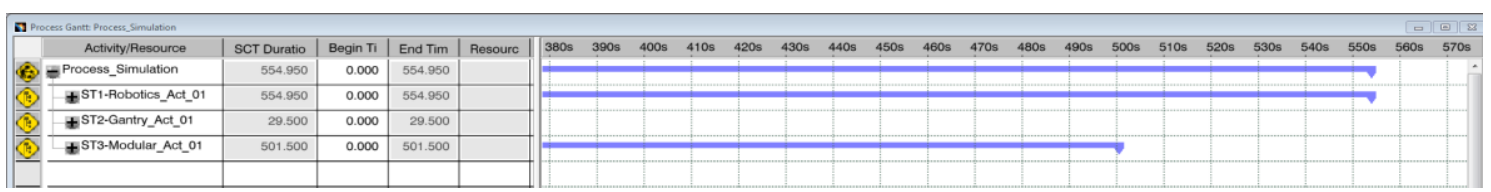

(c)

Figure 10. Process Gantt chart (a) duration 0-190s, (b) 190-380s, and (c) 380-555s 


\begin{tabular}{|c|c|c|c|c|c|}
\hline \multirow{2}{*}{\multicolumn{2}{|c|}{ 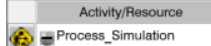 }} & ScT Duratio & Begin $\pi$ & End Tim & Resourc \\
\hline & & 554.950 & 0.000 & 554.950 & \\
\hline (1) & $=$ ST1-Aobotics_Act_01 & 554.950 & 0.000 & 554.950 & \\
\hline (4) & ‡MovePaper & 10.000 & 0.000 & 10.000 & M410iB- \\
\hline (6) & £ MovePallete & 20.000 & 10.000 & 30.000 & M410iB- \\
\hline & t $^{\text {MoveCan_01 }}$ & 10.000 & 30.000 & 40.000 & M410iB- \\
\hline & - WaitMoveBox__1 & 5.000 & 40.000 & 45.000 & \\
\hline & E MoveBox_01 & 13.620 & 45.000 & 58.620 & M410iB- \\
\hline & I MoveCan_02 & 9.010 & 58.620 & 67.630 & M41018- \\
\hline & WaitMoveBox_2 & 5.000 & 67.630 & 72.630 & \\
\hline & $\Phi$ MoveBox_02 & 13.620 & 72.630 & 86.250 & M41018- \\
\hline & \$ MoveCan_03 & 9.010 & 86.250 & 95.260 & M41018. \\
\hline & WaitMoveBox_3 & 5.000 & 95.260 & 100.260 & \\
\hline & I MoveBox_03 & 13.620 & 100.260 & 113.880 & M410iB- \\
\hline & $\Phi^{\text {MoveCan_04 }}$ & 9.010 & 113.880 & 122.890 & M410iB- \\
\hline & WaitMoveBox_4 & 5.000 & 122.890 & 127.890 & \\
\hline & $\Phi^{\text {MoveBox_04 }}$ & 13.620 & 127.890 & 141.510 & $\begin{array}{l}\text { M41018- } \\
\end{array}$ \\
\hline & $\pm^{\text {MoveCan_05 }}$ & 8.000 & 141.510 & 149.510 & M41018. \\
\hline & WaitMoveBox_5 & 5.000 & 149.510 & 154.510 & \\
\hline & \# $^{\text {MoveBox_05 }}$ & 13.620 & 154.510 & 168.130 & M410iB- \\
\hline & 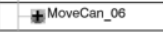 & 9.010 & 168.130 & 177.140 & M410iB- \\
\hline & WaitMoveBox_6 & 5.000 & 177.140 & 182.140 & \\
\hline & $\Phi^{\text {MoveBox_06 }}$ & 13.620 & 182.140 & 195.760 & M410iB- \\
\hline & £MoveCan_07 & 9.010 & 195.760 & 204.770 & M41018- \\
\hline & WaitMoveBox & 5.000 & 204.770 & 209.7 & \\
\hline
\end{tabular}

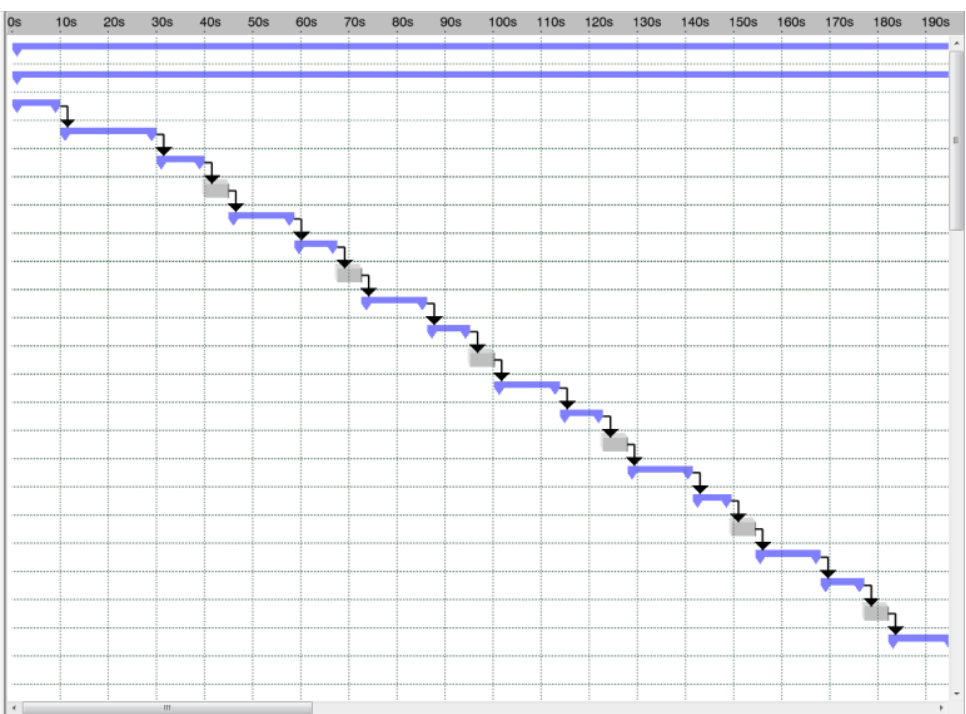

(a)

\begin{tabular}{|c|c|c|c|c|c|}
\hline & Activity/Resource & SCT Duratio & $\operatorname{Begin} \pi$ & End Tim & Resourc \\
\hline (1) & $\Phi^{\text {MoveBox_06 }}$ & 13.620 & 182.140 & 195.760 & M41018- \\
\hline 8) & $\pm^{\text {MoveCan_07 }}$ & 9.010 & 195.760 & 204.770 & M410iB. \\
\hline & - WaitMoveBox_ ${ }^{7}$ & 5.000 & 204.770 & 209.770 & \\
\hline (3) & $\pm^{\text {MoveBox_07 }}$ & 13.620 & 209.770 & 223.390 & M41018- \\
\hline$\overline{7}$ & $\Phi^{\text {MoveCan_08 }}$ & 9.010 & 223.390 & 232.400 & M41018- \\
\hline & - WaitMoveBox__8 & 5.000 & 232.400 & 237.400 & \\
\hline (9) & $\Phi^{\text {MoveBox_08 }}$ & 13.620 & 237.400 & 251.020 & M4101B- \\
\hline & $\Phi^{\text {MoveCan_09 }}$ & 9.010 & 251.020 & 260.030 & M410iB- \\
\hline & - WaitMoveBox_9 & 5.000 & 260.030 & 265.030 & \\
\hline (1) & \# MoveBox__9 & 13.620 & 265.030 & 278.650 & M41018- \\
\hline (8) & \# MoveCan_10 & 9.010 & 278.650 & 287.660 & M410iB- \\
\hline 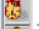 & WaitMoveBox_10 & 5.000 & 287.660 & 292.660 & \\
\hline (3) & E MoveBox_10 & 13.620 & 292.660 & 306.280 & M41018- \\
\hline (9) & \# MoveCan_11 & 9.010 & 306.280 & 315.290 & M41018- \\
\hline (85) & - WaitMoveBox_11 & 5.000 & 315.290 & 320.290 & \\
\hline (2) & $\mathbf{E}^{\text {MoveBox_11 }}$ & 13.620 & 320.290 & 333.910 & M410:B- \\
\hline (1) & E MoveCan_12 & 9.010 & 333.910 & 342.920 & M41018- \\
\hline t5. & WaitMoveBox_12 & 5.000 & 342.920 & 347.920 & \\
\hline (1) & $\Phi^{\text {MoveBox_12 }}$ & 13.620 & 347.920 & 361.540 & M41018- \\
\hline (7) & $\boldsymbol{\Phi}^{\text {MoveCan_13 }}$ & 9.010 & 361.540 & 370.550 & M41018- \\
\hline (9. & - WathoveBox_13 & 5.000 & 370.550 & 375.550 & \\
\hline (3) & 土'MoveBox_13 & 13.620 & 375.550 & 389.170 & M41018- \\
\hline$\because$ & \# MoveCan_14 & 9.010 & 389.170 & 398.180 & M41018- \\
\hline
\end{tabular}

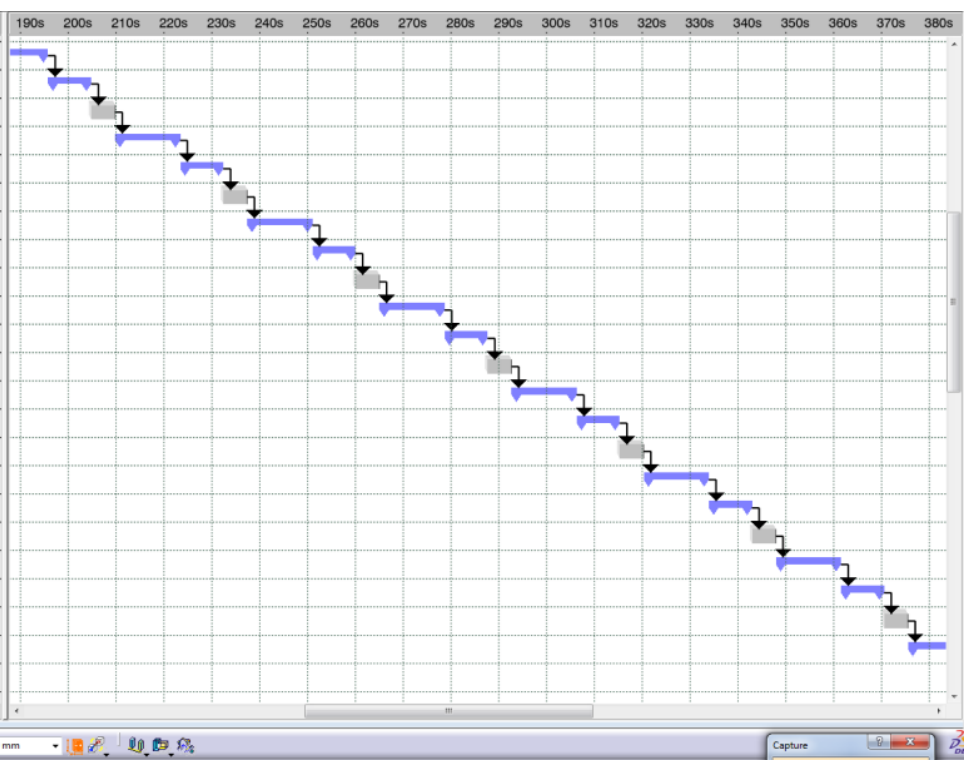

(b)
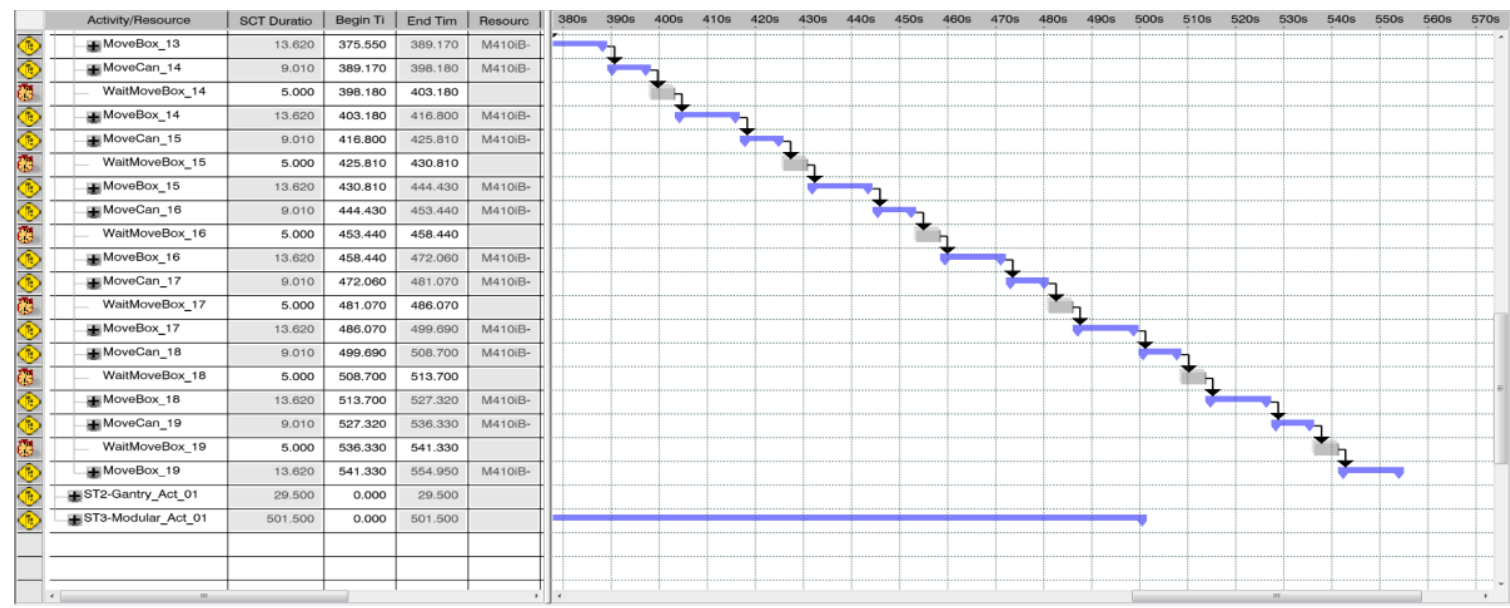

(c)

Figure 11. Robotics Gantt chart (a) duration 0-190s, (b) 190-380s, and (c) 380-555s 


\section{ANALYSIS OF ROBOTIC WORKCELL}

\subsection{Robot cycle time analysis}

Process Gantt chart in Figure 9 shows that the robot cycle time is equal to the total time in the process. Therefore, in this research, only the robot cycle time is analyzed, which is a similar approach to MTM. Cycle time analysis of robot operation is useful for estimating the amount of time required to achieve certain work cycle time prior to the provision of workstation and robot programming [18]. The cycle time of the proposed robotic applications involves some form of material handling in palletizing/de-palletizing and machine loading/unloading applications, in which the robot is used to support an automatic can transferring machine and an automatic carton sealer can be analyzed using the basic cycle time equation as in (3):

$$
T_{c}=T_{o}+T_{h}+T_{w}
$$

where $T_{c}=$ cycle time, $\mathrm{min} / \mathrm{pa} ; T_{o}=$ time of the actual palletizing/de-palletizing, machine loading/unloading operations, $\mathrm{min} / \mathrm{pa} ; T_{h}=$ work part handling, $\mathrm{min} / \mathrm{pa}$; and $T_{w}=$ average waiting time, $\mathrm{min} / \mathrm{pa}$.

According to the Robotics Gantt chart in Figure 10, the robot cycle time can be obtained from the time that the robot manipulator is involved in all activities for aerosol cans packaging and palletizing. In addition, the time of all activities shown on the Robotics Gantt chart can be classified into 5 groups of activities, as shown in Table 2. The robot cycle time, $T_{c}$ can be calculated from (3), which is the total time of all activities is:

$$
\begin{aligned}
T_{c} & =10+20+171.19+95+258.78=554.95 \mathrm{sec} \\
& =9.25 \mathrm{~min} / 19 \text { pas }
\end{aligned}
$$

The production rate of a robotic cell is based on the average production time, which must include the time to set up the cell.

$$
T_{p}=\frac{T_{s u}+Q_{T c}}{Q}
$$

where $T_{p}=$ average production time per work unit, $\min ; T_{s u}=$ setup time, $\min$; and $Q=$ quantity of work units produced in the production run. Production rate is the reciprocal of average production time:

$$
R_{p}=\frac{60}{T_{p}}
$$

where $R_{p}$ is expressed in work units per hour, pa/hr. For long-running jobs, $R_{p}$ approaches the cycle rate $R_{c}$, which is the reciprocal of $T_{c}$. That is, as $Q$ becomes very large $\left(T_{s u} / Q\right) \rightarrow 0$ and

$$
R_{p} \rightarrow R_{c}=\frac{60}{T_{c}}
$$

where $R_{c}=$ operation cycle rate of the machine, $\mathrm{pa} / \mathrm{hr}$; and $T_{c}=$ operation cycle time which takes the longest, $\mathrm{min} / \mathrm{pa}$, from (3).

From the Process Gantt Chart in Figure 9, it can be seen that the $T_{c}$ that takes the longest is $27.63 \mathrm{sec}$, or

$$
T_{c}=27.63 / 60=0.46 \mathrm{~min}
$$

Calculate the production rate from (6) will be:

$$
R_{p}=\frac{60}{0.46}=130.43 \approx 130 \mathrm{pas} / \mathrm{hr}
$$

However, in the actual implementation of the system, and the results of the production rate which is obtained from the fuzzy logic model in section 3.2, the production rate will, therefore, increase by approximately 4 times [19]. Thus

$$
R_{p}=130.43 \times 4=521 \mathrm{pas} / \mathrm{hr}
$$


Table 2. The activities of the robotic manipulator for 19 packs of aerosol can packaging and palletizing

\begin{tabular}{lcc}
\hline \multicolumn{1}{c}{ Activity } & Operation & Time $(\mathrm{sec})$ \\
\hline 1. De-palletizing & Pick + Move + Place + Wait & 10 \\
2. Material handling & Pick + Move + Place + Wait & 20 \\
3. Packaging (19 times) & Pick + Move + Place + Wait & $9.01 \times 19=171.19$ \\
4. Unloading (19 times) & Pick + Move + Wait & $5 \times 19=95$ \\
5. Palletizing (19 times) & Move + Place + Wait & $13.62 \times 19=258.78$ \\
\hline
\end{tabular}

\subsection{Economic analysis}

A new automated CANs packaging cell should be economically evaluated and compared to present production workcells. One important figure, used to determine the value of the investment, is the net present value, which is calculated using (7) where EUAC is the equivalent uniform annual cash, $C_{t}$ is the net cash flow at time $t, n$ is the economic life time of the investment, $A / P$ is the capital recovery factor. Another useful figure is the payback period, which is calculated by solving (8) where $T$ is the payback period.

$$
\text { EUAC }=- \text { Investment cost }(A / P, 30 \%, n)+\text { Annual income }- \text { Operation cost }
$$

$$
\sum_{t=0}^{T} C_{t}=0
$$

Using (7), where investment cost $=7,000,000$ baht, operation cost $=660,000$ Baht $/$ year, annual income $=5,745,600$ Baht, and $A / P$ which $M A R R=30 \%$, and $n=5$ year, will be 0.41058 (note: 30 Bath = 1 US dollar). Thus,

$$
\begin{aligned}
E U A C & =-7,000.000(0.41058)+5,745,600-660,000 \\
& =+2,211,540 \text { Baht }
\end{aligned}
$$

Note: When the result of EUAC is positive, this robot project should be good for investment.

Payback period can be calculated from (8). Thus,

$$
\text { Payback period }=\frac{7,000,000}{5,745,600-660,000}=1.38 \text { years }
$$

\subsection{Analysis of results}

The performance of automated aerosol can packaging and palletizing workcells compared to manually aerosol can packaging and palletizing is shown in Table 3. From the table, it can be seen that the production rate of automated aerosol can packaging and palletizing workcells is 1.42 times higher than manual aerosol can packaging and palletizing. Moreover, the production rate of automated workcells can be increased from $130 \mathrm{pas} / \mathrm{hr}$ to $521 \mathrm{pas} / \mathrm{hr}$ by adding one Cartesian robot to replace working in activity 3, Table 2, because if using only one robot manipulator, there will be a waiting time in this activity to $8 \mathrm{sec} / \mathrm{pa}$ (see Robotics Gantt chart in Figure 10 (a), (b) or (c)). In addition, the workers work 8 hours a day, take a break for 1 hour. For this reason, there will be a setup time every 4 hours. As a result, lead time will be increased. Therefore, the production rate of manual workcells will also be decreased. Furthermore, workers who work in repetitive tasks continuously for a long time experience muscle pain and tenderness of the neck and shoulder areas. The cycle time is therefore increased.

Table 3. The performance of aerosol can packaging and palletizing workcells for product demand $=273,600$ packs

\begin{tabular}{ccccc}
\hline Workcell & Cycle time $(\mathrm{sec})$ & Production rate $(\mathrm{pa} / \mathrm{hr})$ & Total time (hr) & No. of worker (person) \\
\hline Manual packaging palletizing & 100 & 120 & 2280 & 6 \\
Automated packaging palletizing & 29.21 & 521 & 525 & none \\
\hline
\end{tabular}

\section{CONCLUSION}

The cycle time analysis is carried out on the present aerosol can packaging and palletizing and results have shown the need for change to automation in the packaging and palletizing. Thus the development 
of an automated packaging and palletizing system is justified. After implementing the proposed system the cycle time of the operation will be reduced and labour cost will also be reduced. The proposed system can work continuously without much downtime so that significant productivity gain can be obtained. This system requires low maintenance and is easy to install. Further development in the system can be done such as using two robotic manipulators so that the productivity will be improved.

\section{REFERENCES}

[1] H. A. ElMaraghy, "Flexible and Reconfigurable Manufacturing Systems Paradigms," International Journal of Flexible Manufacturing Systems, vol. 17, no. 4, pp. 261-276, 2006.

[2] E. Westkaemper, "Strategic Development of Factories under the Influence of Emergent Technologies," CIRP Annals-Manufacturing Technology, vol. 56, no. 1, pp. 419-422, 2007.

[3] D. Mourtzis, et al., "The Role of Simulation in Digital Manufacturing-Applications and Outlook," International Journal of Computer Integrated Manufacturing, vol. 28, pp. 3-24, 2015.

[4] B. Kádár, et al., "Enhanced control of complex production structures by tight coupling of the digital and the physical worlds," CIRP Annals-Manufacturing Technology, vol. 59, no. 1, pp. 437-440, 2010.

[5] M. Gregor, et al., "Digital Factory," Journal of Automation, Mobile Robotics \& Intelligent Systems, vol. 3, pp. 123$132,2009$.

[6] E. Westkämper, "Digital Manufacturing in the Global Era," in Digital Enterprise Technology: Perspectives and Future Challenges, P.F. Cunha and P. G. Maropoulos, Ed., Boston, MA: Springer, 2007.

[7] F. Hosseinpour and H. Hajihosseini, "Importance of Simulation in manufacturing," World Academy of Science, Engineering and Technology, vol. 51, no. 3, pp. 229-232, 2009.

[8] D. D'Addona and R. Teti, "Manufacturing Cell Lead Time Reduction using Rapid Modelling Technology," in 2nd IPROMS International Researchers Symposium, Ischia, Italy, 2009, pp. 97-100.

[9] A. Caggiano and R. Teti, "Digital Manufacturing Cell Design for Performance Increase," Procedia CIRP, vol. 2, pp. 64-69, 2012.

[10] J. Fleischer, et al., "Quantified Interdependencies between Lean Methods and Production Figures in the Small Series Production," in Manufacturing Systems and Technologies for the New Frontier, London: Springer, 2008.

[11] G. Chryssolouris, Manufacturing Systems: Theory and Practice, New York: Springer-Verlag, 2006.

[12] Glaser, A. Industrial Robots, New York, NY, USA: Industrial Press, 2009.

[13] Caggiano A. and Teti R., "Digital Factory Simulation Tools for the Analysis of a Robotic Manufacturing Cell," in International Conference on Digital Enterprise Technology, Athens, Greece, 2011, pp. 478-485.

[14] P. Dumuid and L. Smith, "Software-Based Design and Simulation of Robotic Assembly Systems", en. Scientific commons .org, 2008.

[15] P.A Farrington, et al., "Increasing the Power and Value of Manufacturing Simulation via Collaboration with Other Analytical Tools: A Panel Discussion," in Proceedings of the Winter Simulation Conference, Phoenix, USA, 1999, pp. 749-753.

[16] J. Nielsen and B. Roth, "On the Kinematic Analysis of Robotic Mechanisms," The International Journal of Robotics Research, vol. 18, no. 12, pp. 1147-1160, 1999.

[17] E. Reuben and A. Moore, "The Effects of Cycle Time on The Physical Demands of A Repetitive Pick-And-Place Task," Applied Ergonomics, vol. 38, no. 5, pp. 609-615, 2007.

[18] M. P. Groover, et al., Industrial Robotics: Technology, Programming, and Application, New York: MeGraw-Hill, Inc., 1986.

[19] K. Srasrisom, et al., "Modeling, analysis and effective improvement of aluminum bowl embossing process through robot simulation tools," International Journal of Procedia Manufacturing, vol. 30, pp. 443-450, 2019.

\section{BIOGRAPHIES OF AUTHORS}

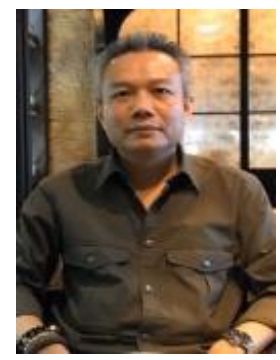

Khongsak Srasrisom is currently a doctorate research student in Advanced Manufacturing Technology, Pathumwan Institute of Technology, Thailand. He is expected to complete his D.Eng. in mid-2020. He has experience in the design and implementation of automated manufacturing systems in the production industry. His research interest is the modeling and simulation of automated manufacturing. Email: khongsaksss67@gmail.com 

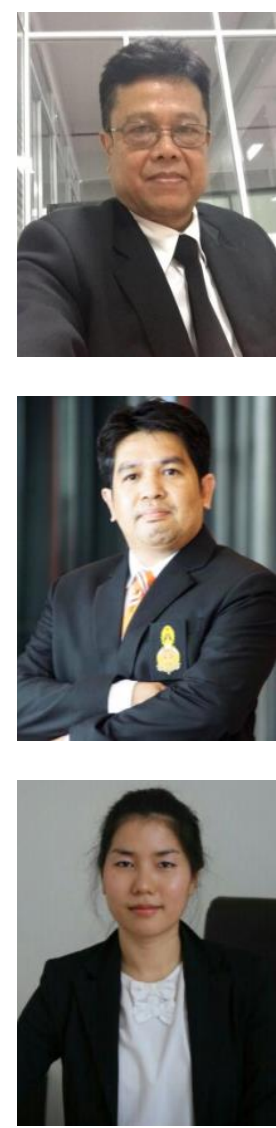

Pramot Srinoi, $\mathrm{PhD}$, is an Associate Professor in the Industrial Engineering Department at the Engineering Faculty, Kasem Bundit University. He received his $\mathrm{PhD}$ in Manufacturing Engineering from Swinburne University of Technology in 2004. Dr. Pramot' research interests include modeling and simulation of automated manufacturing, intelligent manufacturing systems, and mechatronic systems. He has published papers in such journal as International Journal of Production Research, and others. His e-mail address is pramot.srinoi@kbu.ac.th.

Dr. Seksan Chaijit was born in Nakhonsrithummarat, Thailand. He received the B.Eng. degree in Mechatronics Engineering from Pathumwan Institute of Technology, Thailand, the D.Eng. in Information Science and Control Engineering from Nagaoka University of Technology, Japan. His research interests include Material processing, Die-cutting of thin sheet, Finite Element Analysis in material processing and light metal forming. Email: seksan@ pit.ac.th

Dr. Fasai Wiwatwongwana was born in Chiang Mai Province, Thailand. She graduated Ph.D. in Mechanical Engineering from Chiang Mai University in 2012. She has teaching experiences as a lecturer at the Department of Manufacturing Engineering, Pathumwan Institute of Technology from June 2014 to present. She also has experiences as a researcher at Biomedical Engineering Center from March 2008 to May 2013 and Center for Agricultural Biotechnology from July 2007 to February 2008, Chiang Mai University. Email: fasaiw227@gmail.com 